\title{
Coal Seam Roof Crack Evolution Simulation and Gas Drainage Engineering Practice
}

\author{
Sheng-Zhou $\mathrm{LI}^{1,2, \star}$ Ze-Fang SONG ${ }^{1,2}$ and Jun LIU ${ }^{1,2}$ \\ ${ }^{1}$ State Key Laboratory of Gas Disaster Detecting, Preventing and Emergency Controlling \\ chongqing,china \\ ${ }^{2}$ China Coal Technology Engineering Group Chongqing Research Institute chongqing,china \\ *Corresponding author e-mail:Iszaxxl@qq.com
}

Keywords: Fracture development; Gas extraction; Simulation.

\begin{abstract}
After coal mining, rock movement, fracture and stress redistribution of roof and floor surrounding rock are caused and mining-induced fracture field is formed. The fractured zone formed in overlying strata is an important channel and space for gas discharge and storage. The efficient gas drainage can be achieved by placing the drainage borehole in the rich area of fracture development. According to the mining engineering conditions of the 6135 working face of Qidong coal mine, the whole process of overlying strata separation, bending, subsidence, cracking and even upwelling is reappeared by using the method of similar materials simulation and computer numerical simulation. The research results have been successfully applied in engineering practice and obtained significant technical and economic effects.
\end{abstract}

\section{Introduction}

After the coal seam mining, the separation fracture and fracture of the overlying strata penetrated each other to form the dynamic change of the mining fracture field, which provided the channel and space for the pressure relief gas flow and reservoir in the coal seam, and the distribution pattern was closely related to the pressure relief gas extraction [1 2].

Academician Qian Minggao, based on the theory of key layer, applied the method of model experiment and discrete element simulation, proposed the two stage development law of the mining fracture of overlying rock and formed the distribution characteristic of "O" shape circle[3 4]. Li Shugang proposed that the distribution of the fissures in the overlying rock is an "elliptical belt" form [5], and Yuan Liang academician and others put forward the roof ring [6]. Liu Zegong and leaf construction based on the distribution characteristics of "O" shaped ring formed by the overlying strata after coal seam mining, discussed the layout principle of gas drainage tunnel in the roof of the goaf, and analyzed the distribution characteristics of the gas flow field in the goaf before and after the implementation of the roof drainage gas technology with the flow field theory [7 8].

Based on the mining engineering conditions of 6135 working face in qidong coal mine, this paper further analyzes the space-time law and the dynamic change form of mining-induced fracture in overburden rock by means of physical similarity simulation experiment and numerical simulation analysis. According to the height of the rich area of the cracks formed in the 6135 working face of qidong coal mine, this paper provides some theoretical basis for the arrangement of gas drainage system under pressure relief.

\section{Similar Material Simulation of Fracture Evolution Law}

\section{Coal Seam Mining Conditions in Fully Mechanized Coal Caving Face}

Based on the similar material simulation of 61 coal seam mining on the 6135 working face of qidong coal mine, the paper studies the damage law of overburden rock migration in the strike section after coal seam mining. The average dip angle of $6_{1}$ layers of coal is 5 degrees, the trend is $1770 \mathrm{~m}$, and the tendency is $200 \mathrm{~m}$. The average thickness of the $6_{1}$ coal seam in this working face is $1.9 \mathrm{~m}$, and the coal 
seam in the area is complex. The physical and mechanical properties of the top and bottom rock strata are shown in Table 1.

Table 1 Physical and mechanical properties of coal rock strata

\begin{tabular}{ccccccc}
\hline Lithology & $\begin{array}{c}\text { Bulk } \\
\text { modulus } \\
\text { K/GPa }\end{array}$ & $\begin{array}{c}\text { Shear } \\
\text { modulus } \\
\text { G/GPa }\end{array}$ & $\begin{array}{c}\text { tensile } \\
\text { strength } \\
\text { o/MPa }\end{array}$ & $\begin{array}{c}\text { Cohesive } \\
\text { C/MPa }\end{array}$ & $\begin{array}{c}\text { Density } \\
\rho \\
/ \mathrm{Kgm}^{-3}\end{array}$ & $\begin{array}{c}\text { Internal } \\
\text { friction } \\
\text { angle } \varphi /^{\circ}\end{array}$ \\
\hline Mudstone & 5.3 & 2.4 & 3.13 & 2.8 & 2700 & 29 \\
Fine sandstone & 12.23 & 15.6 & 4.41 & 6.5 & 2600 & 35 \\
Medium fine & 15.8 & 20.2 & 6.7 & 9.6 & 2700 & 35 \\
Sandy & 8.1 & 7.9 & 2 & 2.4 & 2600 & 30 \\
Coal & 1.35 & 0.85 & 1 & 1.8 & 1400 & 27 \\
Medium & 9.9 & 17.5 & 4.6 & 7.3 & 2800 & 40 \\
\hline
\end{tabular}

\section{Model Design}

The specification of the frame system of the plane similar material simulation test rig is $3 \mathrm{~m} \times 0.4 \mathrm{~m} \times 2 \mathrm{~m}$. According to the engineering situation of the working face of qidong coal mine 6135 , the simulated working face is $150 \mathrm{~m}$ long and $100 \mathrm{~m}$ high. The simulated mining depth is $750 \mathrm{~m}$. According to the actual situation of the site, the model adopts the method of step-by-step excavation, with each step of $5 \mathrm{~m}$ and a total of 27 steps of $135 \mathrm{~m}$. The boundary condition of the model are set as the horizontal constraint at both ends, the bottom is fixed, and the upper boundary imposes the gravity stress of the rock above it.

According to the requirements of similar material simulation test, the model similar material is composed of quartz sand as aggregate, gypsum, lime and calcium carbonate are used as cementing material, and the water is made up in a certain proportion. The horizontal layer is laid in the model frame, and the layer and layer are sprinkled with the talcum powder. The overlying pressure is calculated according to the model height and the actual buried depth. The initial shape of the model is shown in figure 1.

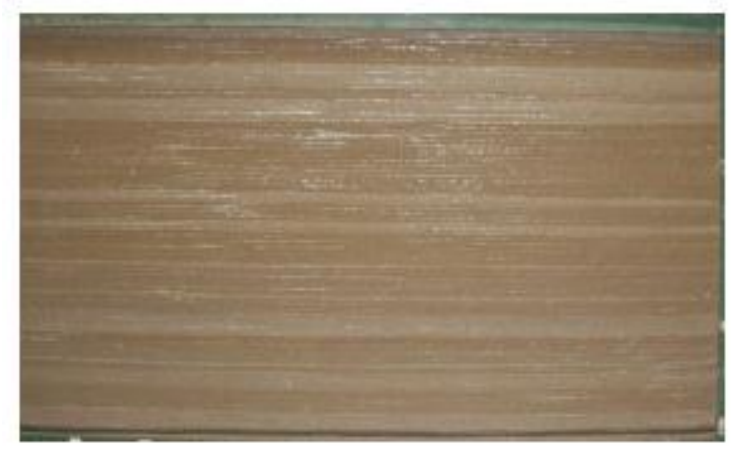

Fig. 1 The initial shape of the model

\section{Experimental Results}

Similar material simulation test can directly reflect the displacement field characteristics of overburden rock and the evolution law of cracks in the process of fully mechanized mining.

When the model excavation is equivalent to the actual working face mining $10 \mathrm{~m}$, a slight dissociation occurred on the direct roof, as shown in figure 2 (a). When the model excavation is equivalent to back mining of working face of $20 \mathrm{~m}$, with the increase of the span distance of rock girder, the direct roof begins to appear large dissociation layer and then collapse, as shown in figure 2 (b).

When the corresponding working face of the model excavation reaches $55 \mathrm{~m}$, the old roof rock beam and the mudstone above it break for the first time, forming the old roof initial pressure, and at 
the same time, there is a small separation layer on the top, and the initial pressure step of the old roof is $55 \mathrm{~m}$. The formation of rock collapse is shown in figure 2 (c).

When the corresponding working face of the model is mined back to $55 \mathrm{~m}$, the old roof rock beam and the mudstone above it are fractured for the first time, forming the initial pressure of the old roof. At the same time, there is a small separation layer on the top, and the initial pressure step distance of the old roof is $55 \mathrm{~m}$. When the model excavation is excavated to $75 \mathrm{~m}$, the old top part of the $2.54 \mathrm{M}$ thick siltstone and the upper peat rock is fractured, forming the first periodic pressure of the old roof, and the periodic pressure step is $40 \mathrm{~cm}$, which is actually $20 \mathrm{~m}$, as shown in Figure 2 (d).

When the actual working face of the model is excavated to $95 \mathrm{~m}$, the $2.7 \mathrm{~m}$ thick fine grained sandstone, the $3.72 \mathrm{~m}$ thick siltstone and the $2.54 \mathrm{~m}$ thick siltstone and the upper mudstone and the upper part of the mudstone are partially separated, and the rock beams are broken again, forming the third cycles of the old roof to press and pressure step from the $17.5 \mathrm{~m}$, the basic top presents the characteristics of the multi rock beam, and the fracture zone will go up. It develops to 60 coal silt sandstone; the maximum height is about $20 \mathrm{~m}$ above the 61 coal roof. The formation of rock formations is shown in Figure 2 (E).

When the actual working face of the model is excavated to $115 \mathrm{~m}$ and $135 \mathrm{~m}$, the old roof has formed fourth times and fifth cycles successively. The final rock collapse form at the end of the model excavation is shown in Figure 2 (f).

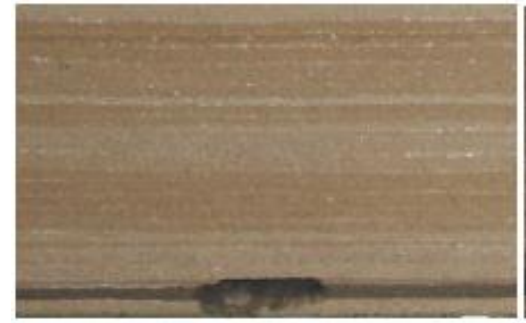

(a)Working face to advance $10 \mathrm{~m}$

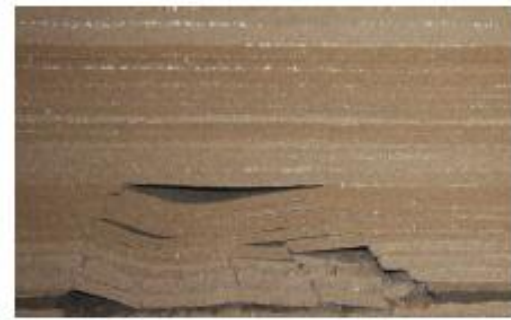

(a)Working face to advance $75 \mathrm{~m}$

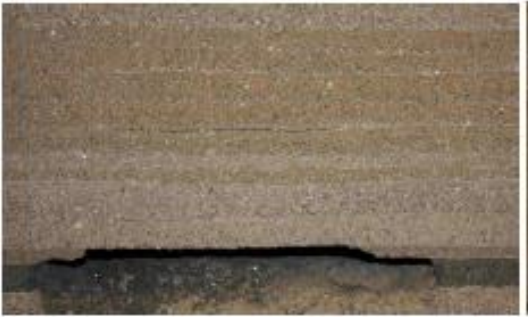

(b) Working face to advance $20 \mathrm{~m}$

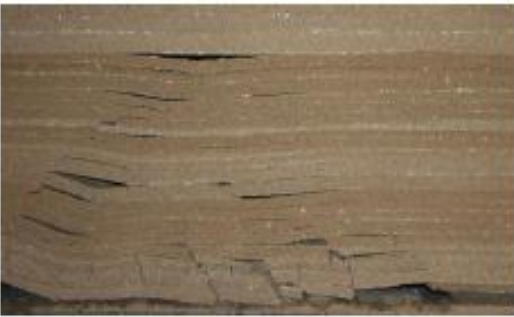

(b) Working face to advance $95 \mathrm{~m}$

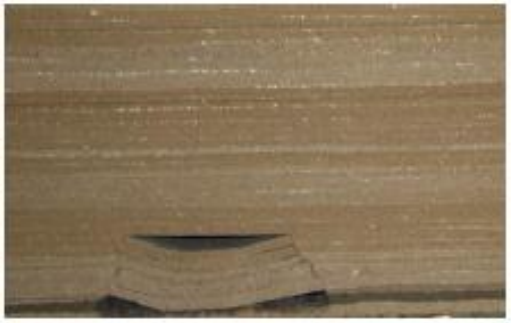

(c) Working face to advance $55 \mathrm{~m}$

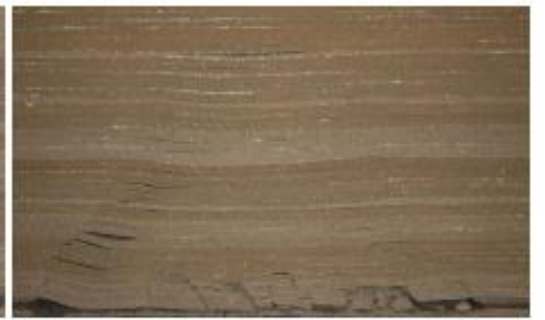

(c) Working face to advance $135 \mathrm{~m}$

Fig. 2 Diagram of rupture of overlying rock at different propelling distance

According to the physical similitude simulation experiment, it can be seen from Fig. 2 that there is no relationship between the horizontal force and the vertical caving block. The fracturing and swelling property of rock mass reduces the subsidence of the upper basic roof rock layer and reduces its failure degree. Only cracks and fractures are produced. Although the original continuity of the rock is destroyed, it does not lose the stratification, and the form and distribution state of the fracture show strong regularity. The overall trend of collapse distance of each layer is decreasing from bottom to top. With the widening of the goaf, the cracks in the middle of the goaf are compacted. The boundary line of crack zone and compaction zone can be approximately straight line. Therefore, under the condition of hard overlying rock, which has little difference in lithology and the development of interbeds, the trapezoidal surface, which is similar to the fracture, can be used in the section perpendicular to the coal seam, as shown in Figure 3. 


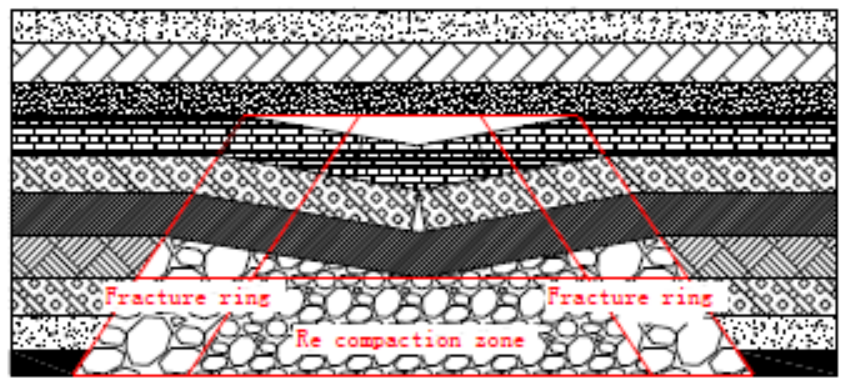

Fig. 3 Diagram of trapezoidal surface of fracture development

Similar to the simulation results show that the qidong well of coal mine 6135 working face of $6_{1}$ layers of coal mining, the scope of the upper goaf 7 30m fracture, the fracture is divided into delamination fracture and vertical fracture fissure, the former is the over strata subsidence in between layer and layer along the plane of fractures, it makes the expansion deformation of coal seam and make the gas pressure relief, and flowing pressure relief gas in the delamination crack; The latter is the perforation fissure formed with the subsidence and fracture of the rock strata, which is the channel to communicate the gas flow between the upper and lower strata.

The high level drilling is arranged in the area with rich fracture development, and the roof crack channel formed by working face backmining is used to extract and enrich the gas in the roof crack around the goaf.

\section{Numerical Simulation of Fracture Evolution Law}

According to the actual working conditions, a numerical simulation model was established using the discrete element numerical calculation program UDEC, as shown in figure 4. UDEC can be used to qualitatively and intuitively observe the collapse rule of roof and provide a basis for drilling hole layout.

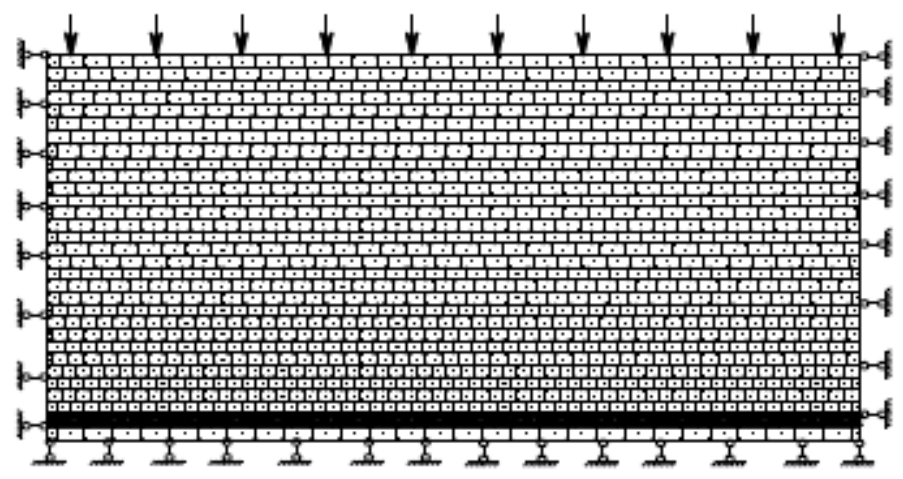

Fig. 4 similar simulation schematic

In order to compare with the similar material simulation test, the simulation test of the numerical simulation of overlying rock fall process is done. As shown in Figure 5, the overlying strata in the coal seam after the coal seam are formed to form the separation fracture and the vertical fracture fracture. After the mining of the working face, the roof of the goaf is bending and sinking under the action of self-weight and overlying strata pressure. When the internal stress exceeds the allowable strength, the caving zone is formed. After the lower rock stratum is destroyed, the upper strata will sink and destroy in the same way, forming a fracture zone. When the rock failure develops to a certain height, the tensile stress within the rock layer is less than the allowed tensile strength, and the rock stratum will only sink and bend, that is, the bend subsidence zone. The strata themselves are continuous, but they will produce abscission layer at the level of subsidence.

It can be seen that the two results are very similar, indicating that the simulation results of similar materials are reliable. 


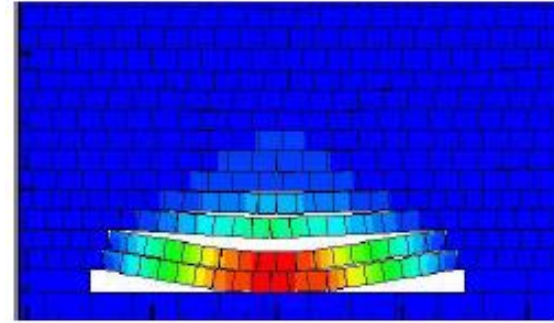

(a) advancing $40 \mathrm{~m}$ in the face

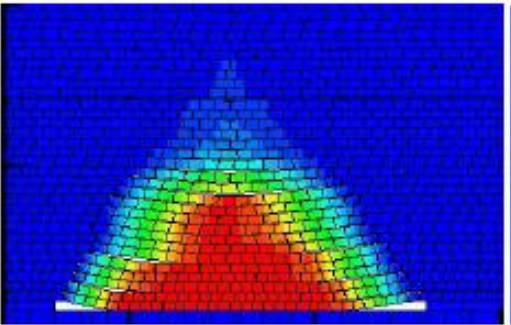

(b) advancing $95 \mathrm{~m}$ in the face

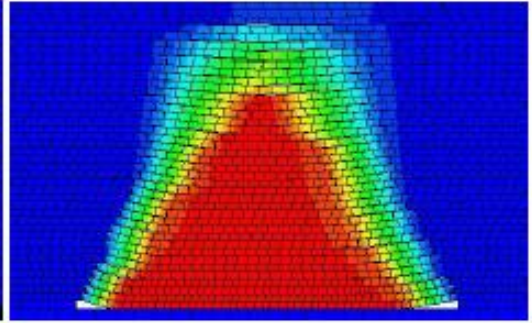

(c) advancing $135 \mathrm{~m}$ in the face

Fig. 5 Dynamic development process of mining overlying rock collapse

\section{Numerical Simulation of Fracture Evolution Law}

The maximum gas emission of 6135 working face in Qidong Coal Mine is $24.4 \mathrm{~m}^{3} / \mathrm{min}$, the air supply is $1700 \mathrm{~m}^{3} / \mathrm{min}$, and the gas concentration is often exceeded. In order to solve the problem of overlimit of gas concentration, a drill field is arranged every $50 \mathrm{~m}$ along the inside side of the wind Lane on the working face, and 3 drills are arranged in each drill, each drill is $20 \mathrm{~m}$ ahead of the front of the drill field. The position of the end hole in the hole is located in the rich zone of fracture development in the top of the goaf. The sealing length of the high hole hole is greater than the height of the mining regular caving belt in the mining seam roof method, and the hole depth of the drilling hole method is more than $10 \mathrm{~m}$.

In the process of high borehole drilling, representative boreholes are selected to conduct single hole concentration and flow investigation. According to the results of fourteenth sets of 2\# boreholes, the concentration and time curve of drilling gas extraction, as shown in Figure 6, are maintained at a high concentration for a long time. The flow rate and time curve of borehole gas extraction, as shown in Figure 7, have a higher gas flow in a period of time. With the continuous extraction, the decrease of flow rate is maintained at a lower value. The gas concentration in the 6135 working face, upper corner and back air flow in Qidong coal mine did not exceed the limit during recovery by high position drilling, and better safety and economic benefits were obtained.

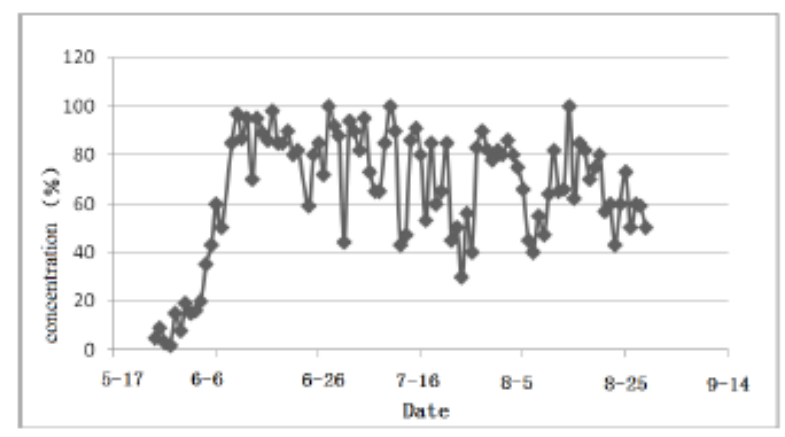

Fig. 6 gas extraction concentration and time curve

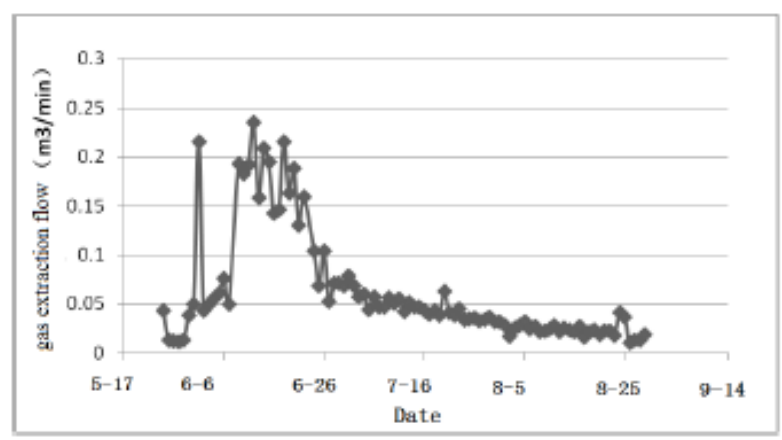

Fig. 7 gas extraction flow and time curve

\section{Conclusions}

Through the similar material test and the computer numerical simulation, the fracture evolution law of the overlying rock, the location and height of the rich area of the fissure are obtained, and the scientific basis is provided for the layout of the high borehole. The gas concentration in the rich area of the fissure area in the goaf can be pumped by the high position drilling, and the gas concentration can be reduced effectively. Better safety and economic benefits. 


\section{Acknowledgments}

This work was financially supported by the National Key Research and Development Program of China (2017YFC0804206), the National Natural Science Foundation of China (51604298), and the Key Laboratory Open Foundation of Anhui Province (KLDCMERDPC14101).

\section{References}

[1] Li Shugang. Activity of surrounding rock and gas migration in fully mechanized top coal caving mining [M]. Xuzhou: China University of Mining and Technology press, 2000.

[2] Li Shugang. Rule and control of gas migration under the influence of surrounding rock activities in fully mechanized top coal caving mining [D] Xuzhou: China University of Mining and Technology, 1998.

[3] Qian Ming Gao, Xu Jialin. Characteristics of "O" circle in mining fracture distribution of overlying strata [J]. Journal of coal science, 1998,23 (5): 466-469.

[4] Xujialin, Meng Guangshi. Gas drainage in goaf by using "O" shape circle characteristics of mining fissures in overlying strata [J].Coal Mine Safety, 1995, 26 (7): 2-4.

[5] Li Shugang. Activity of surrounding rock and gas migration in fully mechanized top coal caving mining [M]. Xuzhou: China University of Mining and Technology press, 2000.

[6] Liu Zegong, Yuan Liang, Dai Guanglong, et al. Research on the mining of gas in a long bore hole in the annular fissure ring of Coal Seam Roof [J]. China Engineering Science, 2004, 6 (5): 32-38.

[7] leaf construction, Liu Zegong. Application of roof draining to goaf gas extraction [J]. Journal of Huainan Industrial Institute, 1999,19 (2): 32-36.

[8] Liu Zegong. Analysis of gas flow field in roof drainage of mining coal seam [J]. mining safety and environmental protection, 2000,27 (3): 4-6. 